\title{
Comparative Study Among Ketamine, Fentanyl, and Ropivacaine, as Pre-incisional Analgesic Given by Surgical Site Infiltration, in Cases Posted for Elective Lower Segment Cesarean Section Under General Anesthesia
}

\author{
Prashant Mishra ${ }^{1}$, Jaybrijesh Yadav ${ }^{2}$, Shubham Rai ${ }^{2}$, Rakesh Bahadur Singh ${ }^{2}$ \\ 1. Anaesthesiology, Rama Medical College \& Hospital, Ghaziabad, IND 2. Anaesthesiology, Uttar Pradesh University of \\ Medical Sciences, Etawah, IND
}

Corresponding author: Rakesh Bahadur Singh, drrakeshsingh27@gmail.com

\section{Abstract}

\section{Aim}

The aim of this study was to evaluate the effect of surgical site infiltration prior to giving incision, with ketamine, fentanyl, and ropivacaine, on perioperative hemodynamic parameters, pain, and any adverse outcomes.

\section{Methods}

The study was carried out on 68 patients divided into four groups of 17 each. After intubation, the study drug was infiltrated subcutaneously at the surgical site, seven min before incision, by the surgeon who was unaware of the injectate. Hemodynamic variables were monitored and recorded during the intraoperative period and postoperative period at one, two, four, six, eight, 12, and 24 hours. The level of sedation was assessed using the Ramsay sedation score (RSS). The fetal outcome was assessed by the APGAR (Appearance, Pulse, Grimace, Activity, and Respiration) score at one, five, and 10 minutes.

\section{Results}

The mean visual analog scale (VAS) scores were significantly $(\mathrm{p}<0.05)$ lower in group A as compared to other groups for most of the postoperative period. Hemodynamic stability was also significantly better with group A as compared to other groups during the perioperative period. The fetal outcome was comparable between the study groups with the APGAR scores similar between the groups at $10 \mathrm{~min}$. However, significantly lower APGAR values were seen in group $C$ as compared to the other study groups, at one and five minutes.

Review began 02/16/2021 Review ended 02/22/2021 Published 02/28/2021

\section{(c) Copyright 2021}

Mishra et al. This is an open access article distributed under the terms of the Creative Commons Attribution License CC-BY 4.0., which permits unrestricted use, distribution, and reproduction in any medium, provided the original author and source are credited.

\section{Conclusion}

Ketamine infiltration resulted in a better hemodynamic profile, a significantly longer duration of the postoperative pain-free interval, and more sedation in the postoperative anesthesia care unit (PACU). It did not affect the fetal wellbeing, as discernable from the APGAR scores.

\section{Categories: Anesthesiology}

Keywords: fentanyl, ketamine, ropivacaine, surgical site infiltration, apgar, vas, rss

\section{Introduction}

Cesarean section (CS) is the most common surgery carried out on women worldwide [1]. Regional anesthesia (RA) is the anesthesia of choice for CS. However, conditions sometimes necessitate the use of general anesthesia (GA) for providing anesthesia in patients posted for CS. Opioids form the backbone of analgesia in GA. However, their use is limited in CS for fear of placental transfer to the fetus and an increased chance of fetal depression. This may lead to a condition, wherein the patient may encounter significant pain in the intraoperative and postoperative periods. Another strategy for relief in incisional and postoperative pain involves the infiltration of the surgical wound with local anesthetic drugs. Preoperative wound infiltration as the method of preemptive analgesia was first addressed as early as 1978 [2]. The concept of preemptive or pre-incisional analgesia focuses on the prevention of central sensitization triggered by surgical incision; however, other factors have been advocated to exaggerate acute and long-term postoperative pain as a result of central sensitization. These include noxious intraoperative stimuli as retraction, postoperative inflammatory processes, and ectopic neural activity [3]. Watanabe et al. studied retrospectively and showed that fentanyl, by continuous subcutaneous infusion, is a useful alternative for cancer pain [4]. Tan et al. found that pre-incisional treatment with subcutaneous infiltration of ketamine prolongs the time to the first analgesic requirement and decreases the total dosage of analgesics used and pain score after 
circumcision surgery [5]. Local wound infiltration with local anesthetics has been suggested to decrease perioperative opioid consumption and postoperative pain [6-7]. Divecha NP et al. concluded that ropivacaine infiltration was more effective for postoperative pain control with better results when done before incision [8]. It has significantly decreased pain intensity and diclofenac sodium consumption and has delayed the first rescue requirement. Although a number of studies have been conducted using ropivacaine, ketamine, and fentanyl as pre-emptive analgesics by surgical site infiltration in various surgeries.

\section{Materials And Methods}

This is a prospective, randomized (computer-generated), double-blind study. The study was undertaken after approval from the ethics committee, UPUMS, Saifai. Informed and written consent was taken and the study was carried out on 68 patients (sample size calculation was based on a population standard deviation of 1.1 with $80 \%$ power and $5 \%$ alpha error and a confidence level of $95 \%$ ) divided into four groups of 17 each, age group 18-40 years, body mass index (BMI) $18-29 \mathrm{~kg} / \mathrm{m}^{2}$, American Society of Anaesthesiologists physical classification I and II (ASA I and II) posted for elective lower segment cesarean section under general anesthesia. Group A ( $\mathrm{n}=17)$ received infiltration at the surgical site with inj ketamine $1.5 \mathrm{mg} / \mathrm{kg}$ diluted up to $20 \mathrm{ml}$, Group B ( $\mathrm{n}=17)$ received infiltration at the surgical site with inj ropivacaine $0.5 \% 20 \mathrm{ml}$, Group C $(\mathrm{n}=17)$ received infiltration at the surgical site with inj fentanyl $100 \mu \mathrm{g}$ diluted up to $20 \mathrm{ml}$, Group D $(\mathrm{n}=17)$ received infiltration at the surgical site with inj normal saline $20 \mathrm{ml}$. In the operating theater (OT) standard monitors were attached and a baseline reading of heart rate (HR), systolic blood pressure (SBP), diastolic blood pressure (DBP), mean arterial pressure (MAP), and peripheral oxygen saturation (SPO2) was recorded. After three minutes of preoxygenation with $100 \%$ O2, patients were induced with inj. thiopentone sodium 5 $\mathrm{mg} / \mathrm{kg}$ body weight and relaxed with inj. succinylcholine chloride $1.5 \mathrm{mg} / \mathrm{kg}$ body weight. Intubation was performed by an experienced anesthetist. Anesthesia was maintained with $0.6 \%$ isoflurane in $50 \%$ nitrous oxide with $50 \%$ oxygen mixture. Seven min before incision, the study drug was infiltrated subcutaneously at the surgical site by the surgeon who was not involved in the study. Hemodynamic variables were monitored and recorded during the intraoperative period. After the completion of surgery patients were shifted to the post-anesthesia care unit (PACU), where the postoperative pain was assessed using a visual analog score $($ VAS $)=0-10$. Hemodynamic parameters were recorded at one, two, four, six, eight, 12, and 24 hours after completion of surgery. Inj diclofenac sodium $75 \mathrm{mg}$ intravenous (IV) was administered as rescue analgesia when VAS score equal to or more than 5 were recorded. The level of sedation was assessed using the Ramsay Sedation Score (RSS). The fetal outcome was assessed by the APGAR (Appearance, Pulse, Grimace, Activity, and Respiration) score at 1, 5, and 10 minutes. All data were compiled systematically and analyzed using mean and standard deviation. Age, body mass index (BMI), duration of surgery, and hemodynamic variables were analyzed using analysis of variance (ANOVA) with post-hoc Bonferroni test. VAS scores, Ramsay Sedation Score, and APGAR scores were compared using the chi-square test. Microsoft Excel (Microsoft Corporation, Redmond, WA) and SPSS version 22 (IBM Corporation, Armonk, NY) software packages were used for data entry and analysis respectively. P-value $<0.05$ is considered statistically significant.

\section{Results}

Table 1 shows the demographic profile and duration of surgery among groups. There was no significant ( $p>0.05$ ) difference in age, body mass index, and duration of surgery among the groups, showing the comparability of the groups in terms of age, BMI, and duration of surgery.

\begin{tabular}{|c|c|c|c|c|c|}
\hline & $\begin{array}{l}\text { Group A Mean } \pm \text { SD } \\
(n=17)\end{array}$ & $\begin{array}{l}\text { Group B Mean } \pm \text { SD } \\
(n=17)\end{array}$ & $\begin{array}{l}\text { Group C Mean } \pm \text { SD } \\
(n=17)\end{array}$ & $\begin{array}{l}\text { Group D Mean } \pm \text { SD } \\
(n=17)\end{array}$ & $\begin{array}{l}\mathrm{p}- \\
\text { value }\end{array}$ \\
\hline Age (years) & $26.65 \pm 3.32$ & $27.94 \pm 4.72$ & $26.53 \pm 2.65$ & $24.76 \pm 3.23$ & 0.210 \\
\hline BMI (kg/m²) & $23.88 \pm 2.11$ & $24.03 \pm 2.39$ & $23.32 \pm 2.40$ & $23.66 \pm 2.05$ & 0.808 \\
\hline $\begin{array}{l}\text { Duration of surgery } \\
\text { (minutes) }\end{array}$ & $52.12 \pm 7.15$ & $49.88 \pm 5.66$ & $52.24 \pm 4.59$ & $52.47 \pm 6.35$ & 0.565 \\
\hline
\end{tabular}

TABLE 1: Demographic profile and duration of surgery among groups

BMI: body mass index

Table 2 shows the intergroup comparison of intraoperative heart rate across time. The intergroup comparison shows that the HR at 0 min after infiltration of the study drug was higher in group D as compared to other groups and is significant $(\mathrm{p}<0.05)$. During the intergroup comparison, the HR at the time of incision (7 min) was found to be significantly higher in group D as compared to groups B and C. During the intergroup comparison, the HR at eight $\min$ (1 min after incision) and $10 \mathrm{~min}$ was observed to be significantly lower in group C as compared to group D. The HR at 20 min was found to be significantly $(\mathrm{p}<$ 0.05 ) higher in groups $C$ and D as compared to group B and was significantly lower in group C as compared to 


\section{Cureus}

group A. The HR after extubation was observed to be significantly $(p<0.05)$ higher in group D as compared to groups $\mathrm{A}, \mathrm{B}$, and $\mathrm{C}$.

\begin{tabular}{|c|c|c|c|c|c|c|c|}
\hline \multirow{2}{*}{\multicolumn{2}{|c|}{ Heart rate (beats per minute) }} & \multicolumn{6}{|l|}{ p-value } \\
\hline & & Group A vs & Group A vs & Group A vs & Group B vs & Group B vs & Group C vs \\
\hline \multicolumn{2}{|l|}{ Baseline } & 1.000 & 1.000 & 0.113 & 1.000 & 0.212 & 0.232 \\
\hline \multicolumn{2}{|l|}{ After Intubation } & 1.000 & 1.000 & 0.064 & 1.000 & 0.086 & 0.879 \\
\hline \multirow{7}{*}{$\begin{array}{l}\text { After infiltration of study } \\
\text { drug }\end{array}$} & 0 Min & 1.000 & 1.000 & 0.000 & 1.000 & 0.000 & 0.000 \\
\hline & $7 \mathrm{~min}$ (time of incision) & 0.289 & 0.824 & 1.000 & 1.000 & 0.011 & 0.048 \\
\hline & $\begin{array}{l}8 \text { min (1 min after } \\
\text { incision) }\end{array}$ & 1.000 & 0.104 & 0.957 & 0.760 & 0.141 & 0.002 \\
\hline & $10 \mathrm{Min}$ & 1.000 & 0.220 & 1.000 & 0.235 & 1.000 & 0.024 \\
\hline & 20 Min & 1.000 & 0.040 & 0.057 & 0.006 & 0.009 & 1.000 \\
\hline & 30 Min & 1.000 & 1.000 & 1.000 & 1.000 & 1.000 & 1.000 \\
\hline & $40 \mathrm{Min}$ & 1.000 & 1.000 & 1.000 & 0.462 & 1.000 & 1.000 \\
\hline \multicolumn{2}{|l|}{ HR after extubation } & 0.857 & 1.000 & 0.000 & 0.165 & 0.046 & 0.000 \\
\hline
\end{tabular}

\section{TABLE 2: Shows the intergroup comparison of intraoperative heart rate across time periods}

HR: heart rate

Table 3 shows the comparison of mean arterial pressure between the groups during the intraoperative period. The MAP at 0 min after infiltration of the study drug was significantly $(p<0.05)$ higher in group D as compared to groups A, B, and D and significantly $(\mathrm{p}<0.05)$ lower in group B as compared to group C. MAP at the time of incision ( $7 \mathrm{~min}$ ) was found to be significantly higher in group A as compared to group B and D. MAP at 20 min was significantly $(p<0.05)$ lower in group $B$ as compared to other groups. The MAP at 30 min being significantly $(p<0.05)$ lower in group D as compared to group C, at $40 \mathrm{~min}$ to be significantly $(\mathrm{p}<0.05)$ lower in group D as compared to group C. The MAP after extubation was significantly $(\mathrm{p}<0.05)$ lower in group A and B as compared to group D, as seen in intergroup comparison. 


\section{Cureus}

\begin{tabular}{|c|c|c|c|c|c|c|c|}
\hline & & \multicolumn{6}{|l|}{ p Value ${ }^{1}$} \\
\hline & & $\begin{array}{l}\text { Group A vs } \\
\text { B }\end{array}$ & $\begin{array}{l}\text { Group A vs } \\
\text { C }\end{array}$ & $\begin{array}{l}\text { Group A vs } \\
\text { D }\end{array}$ & $\begin{array}{l}\text { Group B vs } \\
\text { C }\end{array}$ & $\begin{array}{l}\text { Group B vs } \\
\text { D }\end{array}$ & $\begin{array}{l}\text { Group C vs } \\
\text { D }\end{array}$ \\
\hline Baseline & & 1.000 & 1.000 & 0.191 & 1.000 & 0.388 & 1.000 \\
\hline \multicolumn{2}{|l|}{ After Intubation } & 1.000 & 1.000 & 0.110 & 0.920 & 0.063 & 1.000 \\
\hline \multirow{7}{*}{$\begin{array}{l}\text { After infiltration of study } \\
\text { drug }\end{array}$} & 0 Min & 0.255 & 1.000 & 0.000 & 0.023 & 0.000 & 0.000 \\
\hline & $7 \mathrm{~min}$ (time of incision) & 0.018 & 1.000 & 0.021 & 0.192 & 1.000 & 0.212 \\
\hline & $\begin{array}{l}8 \text { min (1 min after } \\
\text { incision) }\end{array}$ & 0.685 & 0.354 & 0.109 & 1.000 & 1.000 & 1.000 \\
\hline & TO IMIIn & 0.331 & 0.926 & 0.651 & 1.000 & 1.000 & 1.000 \\
\hline & 20 Min & 0.029 & 1.000 & 1.000 & 0.011 & 0.029 & 1.000 \\
\hline & $30 \mathrm{Min}$ & 1.000 & 1.000 & 0.461 & 1.000 & 0.423 & 0.013 \\
\hline & $40 \mathrm{Min}$ & 1.000 & 0.207 & 1.000 & 0.568 & 0.661 & 0.009 \\
\hline After Extubation & & 1.000 & 1.000 & 0.010 & 1.000 & 0.010 & 0.061 \\
\hline
\end{tabular}

TABLE 3: Shows the intergroup comparison of the intraoperative mean arterial pressure across time periods

Table 4 shows the intergroup comparison of HR and mean arterial pressure across time periods among the groups during the postoperative period. HR at one hour was significantly $(\mathrm{p}<0.05)$ higher in group D as compared to other groups, at two hours was significantly $(p<0.05)$ lower in group A as compared to groups $\mathrm{C}$ and $\mathrm{D}$, at four hours was significantly $(\mathrm{p}<0.05)$ higher in group B as compared to other groups, at six hours being significantly $(p<0.05)$ higher in group $B$ as compared to groups $C$ and D. HR at time of rescue analgesia was significantly $(p<0.05)$ higher in groups B and D as compared to groups A and C. Intergroup comparison shows that MAP at one hour was significantly $(\mathrm{p}<0.05)$ higher in group D as compared to other groups, MAP at two hours was significantly $(\mathrm{p}<0.05)$ lower in group A as compared to groups $\mathrm{C}$ and $\mathrm{D}$ and significantly $(\mathrm{p}<0.05)$ lower in group B as compared to group $\mathrm{C}$, at four hours significantly $(\mathrm{p}<0.05)$ higher in group B as compared to other study groups, at six hours was significantly $(p<0.05)$ higher in group A as compared to group D. MAP at the time of rescue analgesia was noticed to be significantly $(p<0.05)$ lower in group A as compared to group D. 


\section{Cureus}

\begin{tabular}{|c|c|c|c|c|c|c|c|}
\hline & Time & p-value & & & & & \\
\hline & & Gr A Vs B & Gr A Vs C & Gr A Vs D & Gr B Vs C & Gr B Vs D & Gr C Vs D \\
\hline & 1 Hour & 1.000 & 1.000 & 0.000 & 1.000 & 0.000 & 0.000 \\
\hline \multirow[t]{8}{*}{ Postop. heart rate } & 2 Hour & 0.187 & 0.025 & 0.016 & 1.000 & 1.000 & 1.000 \\
\hline & 4 Hour & 0.000 & 1.000 & 1.000 & 0.000 & 0.000 & 1.000 \\
\hline & 6 Hour & 1.000 & 0.658 & 0.308 & 0.024 & 0.008 & 1.000 \\
\hline & 8 Hour & 1.000 & 1.000 & 0.680 & 1.000 & 1.000 & 1.000 \\
\hline & 12 Hour & 1.000 & 1.000 & 1.000 & 1.000 & 1.000 & 1.000 \\
\hline & 24 Hour & 1.000 & 1.000 & 0.490 & 1.000 & 0.872 & 0.725 \\
\hline & At rescue analgesia & 0.000 & 1.000 & 0.000 & 0.000 & 0.004 & 0.000 \\
\hline & 1 Hour & 1.000 & 0.131 & 0.000 & 0.007 & 0.000 & 0.002 \\
\hline \multirow[t]{7}{*}{ Postop. mean BP } & 2 Hour & 1.000 & 0.000 & 0.016 & 0.001 & 0.206 & 0.334 \\
\hline & 4 Hour & 0.000 & 1.000 & 1.000 & 0.001 & 0.000 & 0.161 \\
\hline & 6 Hour & 1.000 & 0.470 & 0.044 & 1.000 & 0.393 & 1.000 \\
\hline & 8 Hour & 1.000 & 1.000 & 1.000 & 1.000 & 1.000 & 1.000 \\
\hline & 12 Hour & 0.946 & 1.000 & 1.000 & 1.000 & 0.053 & 0.703 \\
\hline & 24 Hour & 0.240 & 1.000 & 1.000 & 0.462 & 0.075 & 1.000 \\
\hline & At rescue analgesia & $0.20 \%$ & 0.567 & 0.002 & 1.000 & 0.628 & 0.233 \\
\hline
\end{tabular}

TABLE 4: Shows the intergroup comparison of postoperative heart rate and mean arterial blood pressure across time periods

Table 5 shows the intergroup comparison of VAS across the time period during the postoperative period. During the intergroup comparison, VAS at 0 hours was significantly $(p<0.05)$ lower in groups A and B as compared to groups $C$ and $D$ and significantly $(p<0.05)$ lower in group $C$ as compared to group $D$, at one hour significantly lower in groups A and B as compared to other groups, at two hours significantly $(p<0.05)$ lower in groups $\mathrm{A}$ and $\mathrm{B}$ as compared to groups $\mathrm{C}$ and $\mathrm{D}$ and significantly lower in group $\mathrm{A}$ as compared to group B, at four hours was significantly lower in group A as compared to other groups and significantly ( $<<$ 0.05 ) higher in group $B$ as compared to groups $C$ and $D$, at six hours was significantly lower in groups $B$ and $C$ as compared to group D, at eight hours to be significantly higher in group D as compared to other groups, at 12 hours was found to be significantly lower in group A as compared to groups C and D, at 24 hours significantly lower in group A as compared to groups C and D. 


\section{Cureus}

\begin{tabular}{|c|c|c|c|c|c|c|}
\hline & \multicolumn{6}{|l|}{$p$-value } \\
\hline & Group A vs B & Group A vs C & Group A vs D & Group B vs C & Group B vs D & Group $C$ vs $D$ \\
\hline 0 hour & 0.060 & 0.000 & 0.000 & 0.040 & 0.000 & 0.000 \\
\hline 1 hour & 0.004 & 0.000 & 0.000 & 0.020 & 0.000 & 0.000 \\
\hline 2 hour & 0.003 & 0.000 & 0.000 & 0.001 & 0.005 & 0.569 \\
\hline 4 hour & 0.014 & 0.019 & 0.016 & 0.001 & 0.019 & 0.087 \\
\hline 6 hour & 0.229 & 0.122 & 0.059 & 0.030 & 0.045 & 0.000 \\
\hline 8 hour & 0.060 & 0.071 & 0.000 & 0.732 & 0.001 & 0.002 \\
\hline 12 hour & 0.083 & 0.038 & 0.000 & 0.724 & 0.008 & 0.004 \\
\hline 24 hour & 0.368 & 0.048 & 0.003 & 0.338 & 0.027 & 0.014 \\
\hline Time of rescue analgesia & 0.480 & 0.193 & 0.193 & 0.310 & 0.310 & * \\
\hline
\end{tabular}

TABLE 5: Shows intergroup comparison of VAS across time periods in the postoperative period VAS: visual analog score

Table 6 shows the intergroup comparison of RSS across time periods in the postoperative period. According to the intergroup comparison, RSS at 0 hours was significantly $(p<0.05)$ higher in group A as compared to other groups. At two hours, RSS was $2.00 \pm 0.00$ in all groups. No statistics could be computed because RSS was a constant. RSS values were $2.00 \pm 0.00$ in all groups at six, eight, 12 , and 24 hours. RSS at the time of rescue analgesia was significantly $(\mathrm{p}<0.05)$ higher in groups A and C as compared to groups B and D.

\begin{tabular}{|c|c|c|c|c|c|c|}
\hline \multirow{2}{*}{ Time } & \multicolumn{6}{|l|}{$P$ value } \\
\hline & Group A vs B & Group A vs C & Group A vs D & Group B vs C & Group B vs D & Group C vs D \\
\hline 0 hour & 0.015 & 0.037 & 0.015 & 0.310 & * & 0.310 \\
\hline 1 hour & * & 0.310 & * & 0.310 & * & 0.310 \\
\hline 2 hour & * & * & * & * & * & * \\
\hline 4 hour & 0.310 & * & * & 0.310 & 0.310 & * \\
\hline 6 hour & * & * & * & * & * & * \\
\hline 8 hour & * & * & * & * & * & * \\
\hline 12 hour & * & * & * & * & ${ }^{*}$ & * \\
\hline 24 hour & * & * & * & * & * & * \\
\hline Time of rescue analgesia & 0.015 & 1.000 & 0.015 & 0.015 & ${ }^{*}$ & 0.015 \\
\hline
\end{tabular}

TABLE 6: Shows the intergroup comparison of RSS across time periods in the postoperative period

RSS: Ramsay Sedation Scores

Table 7 shows a comparison of APGAR scores between groups. The APGAR scores were found to be significantly lower $(\mathrm{p}<0.05)$ in group $\mathrm{C}$ as compared to other study groups, at one and five min, according to the intergroup comparison. At $10 \mathrm{~min}$, the mean APGAR scores did not differ significantly $(\mathrm{p}>0.05)$ from a statistical point of view. 


\begin{tabular}{|c|c|c|c|c|c|c|}
\hline & \multicolumn{6}{|l|}{ p-value } \\
\hline & Group A vs B & Group A vs C & Group A vs D & Group B vs C & Group B vs D & Group C vs D \\
\hline 1 Min & 0.756 & 0.001 & 0.726 & 0.005 & 0.397 & 0.000 \\
\hline 5 Min & 0.217 & 0.002 & 0.403 & 0.028 & 0.659 & 0.007 \\
\hline 10 Min & 0.528 & 0.415 & 0.486 & 0.939 & 0.587 & 0.589 \\
\hline
\end{tabular}

\section{TABLE 7: Shows intergroup comparison of APGAR scores across time periods}

\section{Discussion}

The present study aims to study the effect of pre-incisional surgical site infiltration of ketamine, ropivacaine, and fentanyl on incisional pain with the primary objective being the assessment of the postoperative pain in the patients using time until use of rescue analgesia and VAS. The secondary objectives of the study were to evaluate any difference between the groups in relation to hemodynamic stability, level of sedation, and fetal outcome. Abdallah NM et al., in their study, assessed the analgesic effectiveness of the pre-incisional infiltration of ketamine following elective abdominal hysterectomy as compared to levobupivacaine [9]. In their study, there was no significant difference between the two groups with regards to blood pressure and heart rate in the postoperative period. However, in our study, there were significant differences between the groups in the context of MAP and HR. Sarhan NA et al. in their study compared MAP and heart rate between the groups receiving ketamine infiltration and the control group [10]. They found MAP at 20 and 30 minutes after injection to be significantly lower in groups receiving ketamine as compared to the control group. However, in our study, no significant difference was found between group A and group D, except at the time of drug infiltration and after extubation. In our study, VAS was significantly lower in the ketamine and ropivacaine group as compared to the other groups in the whole post-operative group, with the ketamine group performing better than the ropivacaine group at one, two, four, eight, and 12 hours. This is in solidarity with the study by Abdallah NM et al., in which they found that VAS in the ketamine group was significantly lower than that in the levobupivacaine group [9]. Safavi M et al., in their study, recorded that VAS scores in ketamine infiltrated groups were significantly lower than in the normal saline infiltrated group [11]. This runs in conjugation with our study. Siddiqui AS et al. also observed similar findings in their study, wherein they found the pain scores to be significantly higher in the group receiving normal saline infiltration in comparison to the groups receiving ketamine infiltration [12]. In our study, RSS at 0 hours was significantly higher in the group receiving ketamine as compared to other groups, indicating greater sedation in the ketamine-infiltrated patients. At the time of rescue analgesia, sedation scores were higher in groups A and C as compared to other groups. For most of the postoperative period, all groups reported an RSS of 2, extending from the first hour itself. Findings on a similar note were reported by El Bahnasawy NS et al. [13]. They reported that the studied groups achieved a score of 1 (awake and oriented) within one hour in the PACU. In the study by Sarhan NA et al., sedation was assessed postoperatively by the Wilson sedation scale [10]. All patients in the three study groups achieved a score of 1 (awake and oriented) within one hour in PACU. In our study, APGAR scores were significantly lower in the fentanyl group as compared to the other three groups at one and five minutes. But, the scores became significantly indistinct at $10 \mathrm{~min}$. This occurs in conjugation with the meta-analysis by Heesen M et al. [14], who found that ketamine administration has no effect on the neonatal outcome. However, our findings contradict the observations by Karbasy SH et al., who, in their study, evaluated the effect of low-dose fentanyl as a premedication before the induction of general anesthesia on the neonatal APGAR score in cesarean section delivery [15]. They concluded that the administration of $1 \mu \mathrm{g} / \mathrm{Kg}$ intravenous fentanyl before the induction of anesthesia for cesarean section delivery does not have any effect on APGAR scores of the neonate in the first and fifth minutes after birth.

\section{Conclusions}

Ketamine infiltration resulted in a better hemodynamic profile, a significantly longer duration of postoperative pain-free interval, more sedation in the postoperative anesthesia care unit (PACU), and did not affect the fetal wellbeing, as discernable from the APGAR scores.

\section{Additional Information}

\section{Disclosures}

Human subjects: Consent was obtained or waived by all participants in this study. Ethical Committee of Uttar Pradesh University of Medical Sciences, Saifai issued approval Ref.

No.:1281/UPUMS/Dean(M)/Ethical/2020-21. Animal subjects: All authors have confirmed that this study 
did not involve animal subjects or tissue. Conflicts of interest: In compliance with the ICMJE uniform disclosure form, all authors declare the following: Payment/services info: All authors have declared that no financial support was received from any organization for the submitted work. Financial relationships: All authors have declared that they have no financial relationships at present or within the previous three years with any organizations that might have an interest in the submitted work. Other relationships: All authors have declared that there are no other relationships or activities that could appear to have influenced the submitted work.

\section{Acknowledgements}

We would like to thank the patients of UPUMS, Saifai, Etawah, UP, India, who participated in the study and the PG students (department of anesthesia) for collecting the data. We are also very grateful to our family members and colleagues for their constant support and guidance.

\section{References}

1. Mathai M, Hofmeyr GJ, Mathai NE: Abdominal surgical incisions for caesarean section. Cochrane Database Syst Rev. 2013, 5:004453. 10.1002/14651858.CD004453.pub3

2. Neil RS: Postoperative analgesia following brachial plexus block. Br J Anaesth. 1978, 50:379-382. 10.1093/bja/50.4.379

3. Katz J, Seltzer Z: Transition from acute to chronic postsurgical pain: risk factors and protective factors . Expert Rev Neurother. 2009, 9:723-744. 10.1586/ern.09.20

4. Watanabe S, Pereira J, Hanson J, Bruera E: Fentanyl by continuous subcutaneous infusion for the management of cancer pain: Aa retrospective study. J Pain Symptom Manage. 1998, 16:323-326. 10.1016/s0885-3924(98)00095-5

5. Tan PH, Cheng JT, Kuo CH, et al.: Preincisional subcutaneous infiltration of ketamine suppresses postoperative pain after circumcision surgery. Clin J Pain. 2007, 23:214-218. 10.1097/AJP.0b013e31802e3377

6. Koeppe T, Constantinescu MA, Schneider J, Gubisch W: Current trends in local anesthesia in cosmetic plastic surgery of the head and neck: results of a German national survey and observations on the use of ropivacaine. Plast Reconstr Surg. 2005, 115:1723-1730. 10.1097/01.prs.0000161671.34502.40

7. Bisgaard T, Klarskov B, Kristiansen VB, et al.: Multi-regional local anesthetic infiltration during laparoscopic cholecystectomy in patients receiving prophylactic multi-modal analgesia: a randomized, double-blinded, placebo-controlled study. Anesth Analg. 1999, 89:1017-1024.

8. Divecha NP, Mehta K, Panchal SB: Comparison of pre incisional versus post incisional infiltration with $0.5 \%$ ropivacaine for post-operative analgesia in patients of open cholecystectomy under general anaesthesia. Int J Med Res. 2018, 3:22-24.

9. Abdallah NM, Salama AK, Ellithy AM: Effects of preincisional analgesia with surgical site infiltration of ketamine or levobupivacaine in patients undergoing abdominal hysterectomy under general anesthesia; a randomized double blind study. Saudi J Anaesth. 2017, 11:267-272. 10.4103/1658-354X.206794

10. Sarhan NA, Fatahalla MA, Ahmed MEM, Osman HAM: Analgesic effect of pre-incisional peritonsillar infiltration of ketamine for post-tonsillectomy pain in children. Int J Otorhinolaryngol Head Neck Surg. 2018, 7:317-329. 10.4236/ijohns.2018.76032

11. Safavi M, Honarmand A, Nematollahy Z: Pre-incisional analgesia with intravenous or subcutaneous infiltration of ketamine reduces postoperative pain in patients after open cholecystectomy: a randomized, double-blind, placebo-controlled study. Pain Med. 2011, 12:1418-1426. 10.1111/j.1526-4637.2011.01205.x

12. Siddiqui AS, Raees US, Siddiqui SZ, Raza SA: Efficacy of pre-incisional peritonsillar infiltration of ketamine for post-tonsillectomy analgesia in children. J Coll Physicians Surg Pak. 2013, 23:533-537.

13. El Bahnasawy NS, Abu-Samra M: The analgesic efficacy of preincisional peritonsillar versus intravenous ketamine with bupivacaine infiltration for tonsillectomy in children: a randomized double blind controlled study. Ain-Shams J Anaesthesiol. 2014, 7:514-517. 10.4103/1687-7934.145685

14. Heesen M, Bohmer J, Brinck EC, Kontinen VK, Klohr S, Rossaint R, Straube S: Intravenous ketamine during spinal and general anaesthesia for caesarean section: systemic review and meta-analysis. Acta Anaesthesiol Scand. 2015, 59:414-426. 10.1111/aas.12468

15. Karbasy SH, Derakhshan P: The effect of low dose fentanyl as a premedication before induction of general anaesthesia on the neonatal APGAR score in caesarean section delivery: randomized, double-blind controlled trial. Med J Islam Repub Iran. 2016, 27:361. 